\title{
AC 2011-1115: ALIGNMENT OF PREPARATION VIA FIRST-YEAR PHYSICS MECHANICS AND CALCULUS COURSES WITH EXPECTATIONS FOR A SOPHOMORE STATICS AND DYNAMICS COURSE
}

\section{Kristi J Shryock, Texas A\&M University}

Kristi J. Shryock is a Lecturer and Director of Undergraduate Programs in the Department of Aerospace Engineering at Texas A\&M University. She received both a B.S. and M.S. in Aerospace Engineering from Texas A\&M and received her Ph.D. in Interdisciplinary Engineering at Texas A\&M in May 2011. Her research work focuses on engineering education.

\section{Prof. arun r srinivasa, Texas A\&M University, Department of Mechanical Engineering}

Prof. Srinivasa received his batchelor's degree in mechanical engineering from the Indian Institute of Technology, Madras in 1986 and his Ph. D from the University of California at Berkeley. He is currently a professor in the mechanical engineering department and serves as a curriculum coordinator for the Freshman engineering program at the Dwight Look College of Engineering at Texas A\&M University

\section{Jefferey E. Froyd, Texas A\&M University}

Jeffrey E. Froyd is the Director of Faculty Climate and Development at Texas A\&M University. He served as Project Director for the Foundation Coalition, an NSF Engineering Education Coalition in which six institutions systematically renewed, assessed, and institutionalized their undergraduate engineering curricula, and extensively shared their results with the engineering education community. He co-created the Integrated, First-Year Curriculum in Science, Engineering and Mathematics at Rose-Hulman Institute of Technology, which was recognized in 1997 with a Hesburgh Award Certificate of Excellence. He has authored or co-authored over 70 papers on engineering education in areas ranging from curricular change to faculty development. He is collaborating on NSF-supported projects for (i) renewal of the mechanics of materials course, (ii) improving preparation of students for Calculus I, (iii) systemic application of concept inventories. He is currently an ABET Program Evaluator and a Senior Associate Editor for the Journal on Engineering Education. 


\section{Alignment of Preparation via First-year Physics Mechanics and Calculus Courses with Expectations for a Sophomore Statics and Dynamics Course}

Anecdotally, engineering faculty members complain students taking sophomore engineering science courses are not prepared with respect to mathematics and physics. In response, faculty members from mathematics and/or physics contend their courses have adequately prepared students in terms of needed knowledge and skills in their respective subjects. However, these conversations are rarely supported by carefully analyzed data with respect to key questions. Therefore, the authors have initiated a study to address questions including the following:

- For sophomore engineering science courses, what is expected with respect to mathematical preparation?

- For sophomore engineering science courses, what is expected with respect to preparation in physics mechanics?

- To what extent are the expectations with respect to mathematics preparation aligned with the topics covered in first-year calculus courses?

- To what extent are the expectations with respect to physics mechanics preparation aligned with the topics covered in first-year physics mechanics course?

To answer the first two questions for a sophomore engineering course in statics and dynamics at a large public university, the authors used a matrix to analyze all of the homework and exam problems to see what knowledge and skills in mathematics and physics mechanics were needed to answer the questions. Validity of the analysis was checked by asking two doctoral students in mechanical engineering to analyze a randomly selected subset of the problems to determine to what extent their analysis agreed with the original analysis. Instead of asking one or more engineering faculty members for their expectations, analyzing homework and exam problems allowed the analysis to be based on actual evidence from an offering of the course instead of perceptions of faculty members about what they might want. From this analysis, a list of skills in mathematics and physics mechanics was constructed.

To answer the last two questions, the student compared the list of knowledge and skills to the syllabi and table of contents for the first-year mathematics and physics mechanics courses. The paper will present results of these analyses and offer insights in terms of where the courses were well aligned and where alignment could benefit from further attention. Hopefully, this analysis will provide a firmer basis for future conversations about alignment between engineering science courses and the first-year courses that are, in part, expected to prepare students for these courses.

\section{Introduction}

Student knowledge and skill with respect to mathematics and physics is a major part of the foundation for their progress in mastering an engineering discipline. ABET Engineering Criteria require that at least twenty-five percent of the credits for an engineering program be taken in mathematics and science courses, and some of the science courses for mechanical engineering curricula are expected to be in physics ${ }^{1}$. At least one study ${ }^{2}$ has shown that success in the first mathematics course is useful in predicting persistence in an engineering program. While importance of mathematics and physics for success in studying engineering is unquestioned, 
deeper understanding of both how engineering faculty members expect their students to apply mathematics and physics and the extent to which engineering students are prepared to satisfy the expectations of their faculty members is required. In addition, the alignment of the expectations engineering faculty members have of skills needed by their entering students to what is actually utilized in the classroom must also be addressed. Therefore, the paper intends to address four questions:

- For sophomore engineering science courses, what is expected with respect to mathematical preparation?

- For sophomore engineering science courses, what is expected with respect to preparation in physics mechanics?

- To what extent are the expectations with respect to mathematics preparation aligned with the topics covered in first-year calculus courses?

- To what extent are the expectations with respect to physics mechanics preparation aligned with the topics covered in first-year physics mechanics course?

\section{Background}

At least as far back as the 1960s, researchers began to discover that learners offered explanations for physical phenomena that were at odds with common scientific understanding ${ }^{3}$. For example, researchers found that many learners thought that forces needed to be exerted on bodies so that they would continue to move at constant, non-zero velocities. Perhaps the most intriguing result of this research was that learners retained their belief in the alternative explanations, even after instruction. Today, a multi-disciplinary research field studies conceptual understanding of learners, including what is conceptual understanding, how conceptual understanding can be assessed, what are common alternative explanations that learners offer for physical phenomena, and how learners can be influenced, so that their explanations reflect common scientific understanding ${ }^{4}$. Duit maintains an active bibliography for this field that contains over 8000 references 5 .

Evaluating how mathematics from the first year is used downstream in the engineering curriculum is not new. In 1974, the Committee on Curricular Emphasis in Basic Mechanics (CCEBM) was formed out of concern within the Mechanics Division of ASEE for the quality of instruction in basic mechanics. This led to the development of an extensive national survey and preparation of a readiness skills test for students entering their first engineering mechanics course. The test focused on providing "hard" data for proper discussions on the emphasis and coverage of basic mathematic skills that are prerequisites to mechanics. It consisted of questions related to both pre-college and college-level mathematics that serve as prerequisites to the mechanics course. Given on a trial run to a few institutions in 1976 and then nationally to 9,500 students in 1977, it provided convincing evidence of the lack of mathematics preparation students bring into the mechanics curriculum. Students received an average of 12.8 correct responses out of a total of 25 questions $^{6}$. The test was revisited in 1987 and given to 3,850 students to see if any significant changes had occurred. The exact same version of the test was administered, so direct comparisons could be made. While the average number of correct responses did increase to 13.7 in 1987, closer inspection of the data actually showed a wider spread between schools participating. Snyder felt this change might be due to a potential softening of entrance requirements ${ }^{7}$. In either administration, an average score of $55 \%$ was 
considered much lower than the expected average score of 75\%. Snyder stated in his 1988 review that, "The dismal results on this test substantiate the allegations that our students as a group are seriously deficient in their understanding and ability to use even elementary tools of mathematics...It is no wonder that students have difficulty learning mechanics in our basic courses; they have to spend much of their time relearning elementary mathematics." (p. 1346) ${ }^{7}$

Studies such as the ones cited in the preceding paragraph may have contributed to the motivation for the Neal Repot ${ }^{8}$, which emphasized the need for postsecondary institutions to reform undergraduate science, technology, engineering, and mathematics (STEM) education. Like all other STEM fields, mathematics departments found themselves trapped in institutional structures that assumed that the instructional practices that had evolved since the late 1950s were appropriate and acceptable ${ }^{9}$. As result of such practices U.S. students have been left with less than acceptable quantitative skills with respect to requirements for future study or careers ${ }^{9}$. Findings from this study were echoed in a recent study supported by the Mathematics Association of America (MAA) ${ }^{10}$. Mathematicians, who led the study, brought together groups of engineering and computer faculty members as well as other downstream consumers students who took mathematics courses. Summarizing conversations of the different disciplinary faculty, Ganter and Barker ${ }^{10}$ reported concerns about the mathematics preparation of undergraduate students for their disciplinary courses.

Stimulated by the Neal report and the willingness of the Federal Government to support National Science Foundation (NSF) grants for innovation in undergraduate STEM education, NSF initiated several major initiatives to promote new STEM curricula. One initiative was the Calculus Reform Movement ${ }^{11}$. According to studies funded during the movement, students felt more positive about calculus and perceived they were better prepared ${ }^{12,13,14,15}$. However, little data has been generated to support assertions that reform efforts have had a significant impact on downstream engineering courses ${ }^{16}$. Manseur, et al. ${ }^{17}$ reported that little progress has been made in mathematics education in engineering. They admitted that teaching needs to be different, but they were not sure how to accomplish this. "Furthermore, engineering faculty members still report there are disconnects between the knowledge that students gain in mathematics courses and their ability to apply such knowledge in engineering situations ${ }^{18}$."

Work on conceptual understanding, including the FCI, the FMCE, the SSI, and SCI, has provided considerable information about how students understand (or misunderstand) concepts in many different subjects ${ }^{19,20,21,22,23,24,25,26}$. In addition, the MBT provides information about abilities to solve problems in physics mechanics ${ }^{27}$. However, the research does not provide explicit articulation of what engineering faculty members who teach core engineering courses that require physics mechanics as prerequisite knowledge think their students should know and be able to do at the beginning of one of these courses. Nor does the research shed light on how well students satisfy expectations of their faculty members. In addition, the authors could find no studies that addressed either expectations for mathematical knowledge and skills for specific core engineering courses or the degree to which engineering students beginning a core engineering course satisfied these expectations. Therefore, this gap motivates the research described in the following sections.

\section{Methods}


To determine expectations of engineering faculty for the knowledge of mathematics and physics mechanics and skill in applying this knowledge that students in their course should have to be successful, the authors identified a core, required, sophomore-level engineering science course in the mechanical engineering curriculum. While students complete several engineering courses in their sophomore-year, including statics and dynamics, materials, thermodynamics, and numerical methods, the course selected is a statics and dynamics course that resembles many courses in mechanical engineering curricula across the world because it is the most calculus and physics intensive. For mechanical engineering students, they are expected to apply what they learned in their first-year calculus and calculus-based mechanics physics courses, as well as the mathematics and physics they learned in high school. Also, the course is a direct prerequisite for more follow-on courses in different engineering programs, including being a direct prerequisite to five follow-on courses in the mechanical engineering curriculum. It also lies in the critical path to degree for students. Taught as a service course in the mechanical engineering department, over 1,300 engineering students per year enroll in the statics and dynamics course, or a similar course, from almost all engineering majors at the institution. In addition, since it is taught as a service course for many other departments, the curriculum is common among the different sections of the course, and standardized sets of exams are utilized. For these reasons, it is relatively easy to extract necessary data for comparison. The importance of this course in an engineering curriculum was conveyed by Danielson and Danielson ${ }^{28}$ who determined, "Success in latter courses is directly correlated to success in statics."

\section{1) Analysis of Exam and Homework Problems in Statics and Dynamics Course}

To answer the first two questions for a sophomore engineering course in statics and dynamics at a large public university, the authors asked engineering faculty members who teach the course for problems they felt illustrated the prerequisite mathematics and physics mechanics knowledge and skills students should have mastered when they entered the course. The authors felt this would be more informative than asking for a long list of expectations as faculty could have misconceptions regarding what skills they think students should be able to do and what is actually needed in their course. While the faculty members provided several problems related to mathematics skills necessary for the course, fewer problems related to physics mechanics skills were submitted. In fact, several of the physics mechanics problems submitted were actually mathematics-related skills and not directly physics mechanics skills. An example is shown in Figure 1.

\section{Figure 1. Example Physics Mechanics Problem Submitted by Engineering Faculty Member} (forthcoming)

The authors then used a matrix to analyze 151 homework and exam problems to see what knowledge and skills in mathematics and physics mechanics were needed to answer the questions. Instead of asking one or more engineering faculty members for their expectations, analyzing homework and exam problems allowed the analysis to be based on actual evidence from an offering of the course instead of perceptions of faculty members about what they might want. This process also provided some insight into the alignment of skills engineering faculty felt were necessary to be successful in the course and those that are actually utilized in the 
course. From this analysis, a list of skills in mathematics and physics mechanics was constructed (see Figure 2).

Figure 2. Portion of Q-matrix Used to Determine Skills in Homework and Exam Problems

\begin{tabular}{|l|c|c|c|c|}
\hline & \multicolumn{5}{c|}{ Homework Problems } \\
\hline \multicolumn{1}{|c|}{ Skills } & $3-1$ & $3-5$ & $3-6$ & $3-47$ \\
\hline MATH & & & & \\
\hline resolve vectors into components (2-D) & & & & \\
\hline resolve vectors into components (3-D) & 0 & 1 & 1 & 0 \\
\hline simultaneous equations & 0 & 1 & 1 & 1 \\
\hline & & & & \\
\hline PHYS & & & & \\
\hline free-body diagram & 1 & 1 & 1 & 1 \\
\hline circular motion & 0 & 0 & 0 & 0 \\
\hline Pulleys & 0 & 0 & 0 & 0 \\
\hline Friction & 0 & 0 & 0 & 0 \\
\hline
\end{tabular}

Validity of this analysis was checked by asking two doctoral students in mechanical engineering to analyze a randomly selected subset of problems to determine to what extent their analysis agreed with the original analysis. Results between the comparisons were very close. Differences occurred when different methods could be used to solve a problem when the problem statement did not dictate what method to use. This brought to light the issue of engineering faculty members having the course material they teach being aligned with their expectations. For example, multiple engineering faculty members had included problems involving solving for projection of vectors. When the analysis of the homework and exam problems was completed, there was not a single problem that specifically asked students to find the projection between two vectors. While it was definitely a tool that could be used and one of the doctoral student reviewers had listed it as a skill used in several of the homework problems, students were not explicitly asked to use it, based on the homework and exam problems.

\section{2) Analyze Alignment with Mathematics and Physics Courses}

To answer the last two questions, the authors compared the list of knowledge and skills to the syllabi and table of contents for the first-year mathematics and physics mechanics courses. The resulting set of mathematics topics identified by faculty as necessary for student mastery are listed in Figure 3. In addition, the comparison between percentage of homework and exam problem covering these topics and percentage of time spent in first-year calculus courses on the topics according to the course syllabi are detailed in the figure.

Figure 3. Alignment of First-year Mathematics Topics 


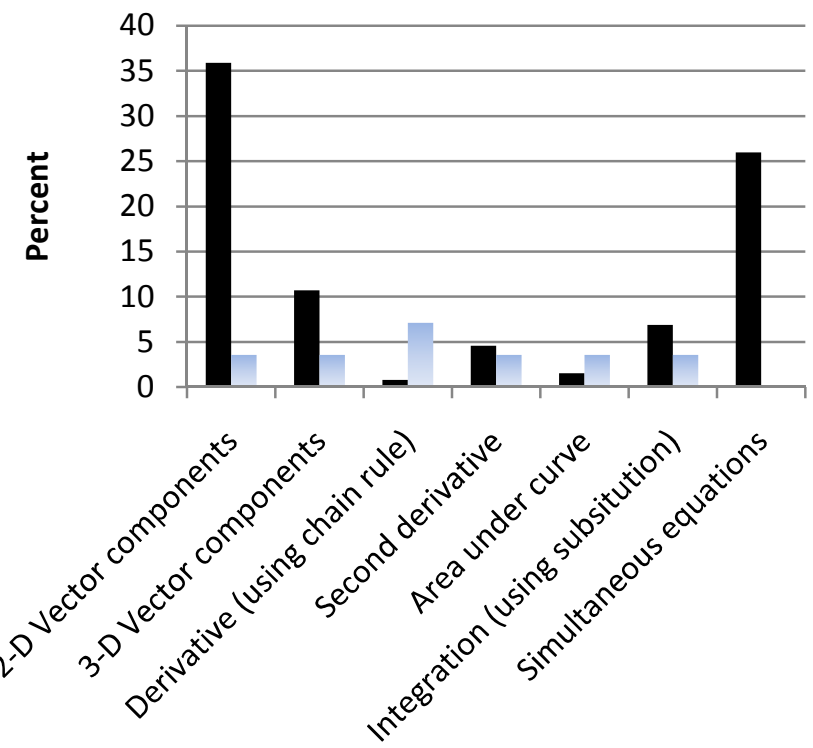

- statics and dynamics hw and exam questions

first-year calculus coverage on syllabi

From the figure, serious alignment issues are evident. For example, important mathematics skills in the statics and dynamics homework and exam problems include two-dimensional vectors and simultaneous equations. These two topics are briefly listed as topics on the calculus syllabi, if at all.

The resulting set of physics mechanics topics identified by engineering faculty members as necessary for student mastery are listed in Figure 4. The respective percentages described in Figure 3 relating to physics mechanics are shown in this figure.

Figure 4. Alignment of First-year Physics Mechanics Topics

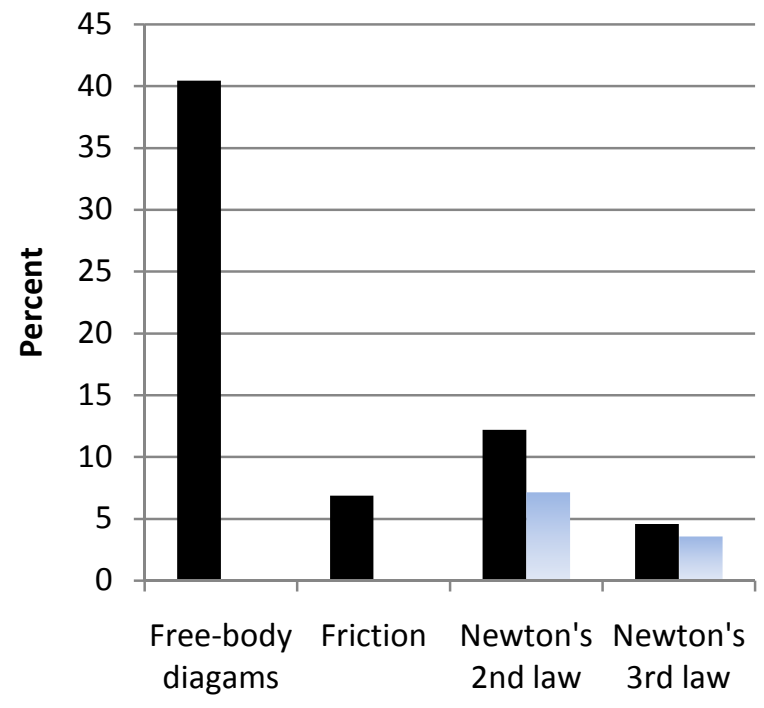

- statics and dynamics hw and exam questions

first-year physics coverage on syllabus 
Again, an issue of alignment between topics taught in the physics mechanics course and topics utilized in the statics and dynamics course are highlighted. It is important to show that even though the topic is listed on the syllabus for the course and in the table of contents for the textbook utilized in the courses, differences in coverage are still possible. For example, the notation used in teaching the material or the exact amount of time spent covering the information in reality is beyond the scope of the analysis of this paper. A quick review of the material in the textbook utilized in the physics mechanics class related to free-body diagrams does reveal further information on the importance of notation. Figure 5 depicts a free-body diagram shown on page 21 of the University Physics textbook by Young and Freedman ${ }^{31}$. Because the physics mechanics class teaches mainly kinematics in the class, most of the free-body diagrams have objects that are moving. In addition, most all of the free-body diagrams in the physics textbook include the acceleration vector.

Figure 5. Free-body Diagram from Physics Textbook ${ }^{31}$

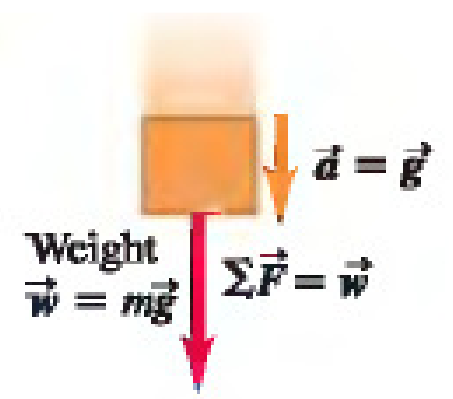

Traditional engineering statics and dynamics textbooks refrain from including the acceleration vector information on the free-body diagram. Students are instructed to only include forces acting on the body in question on the free-body diagram. Figure 6 shows a typical engineering free-body diagram shown on page 166 of the Vector Mechanics for Engineers statics and dynamics textbook by Beer and Johnson ${ }^{32}$. This simple illustration helps explain why $39 \%$ of students completing a physics mechanics pre-test in a sophomore-level statics and dynamics course selected an answer choice for free-body diagram questions that contained a velocity vector.

Figure 6. Free-body Diagram from Engineering Statics and Dynamics ${ }^{32}$

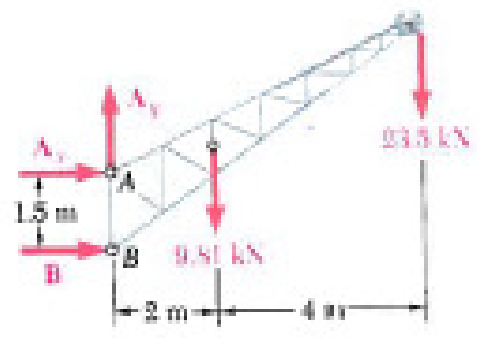

\section{Conclusion}

In review of the first-year mathematics and physics mechanics courses, the authors found that two different alignment issues. First of all, engineering faculty members themselves were not 
completely aligned with the topics they felt were utilized and necessary to be successful in the statics and dynamics course and the topics they required in homework and exam questions. Evaluating each of the homework and exam questions in the class helped showcase the skills used in the class. Secondly, while many of the topics identified as necessary for a sophomorelevel statics and dynamics course were listed on the syllabi for the courses, there was a disproportion between the amount of coverage received in the first-year courses and the utilization of these skills based on the number of homework and exam problems related to them. In addition, it was shown that simply because a topic is listed on the course syllabus does not provide enough information to determine the notation used when teaching the material or the actual time spent covering the material.

\section{Bibliography}

1. ABET, Criteria for Accrediting Engineering Programs: Effective for Evaluations During the 2010-2011 Accreditation Cycle. 2010, Baltimore, MD: ABET Engineering Accreditation Commission.

2. Budny, D., Bjedov, G., \& LeBold, W. (1997). Assessment of the Impact of the Freshman Engineering Courses. 1997 FIE Conference Proceedings.

3. Gentner, D, \& Stevens, A. L. (1983) Mental Models, Hillsdale, NJ: Lawrence Erlbaum Associates, Inc.

4. references forthcoming

5. Duit, R. (2009). Bibliography - Students' and Teachers' Conceptions and Science Education (STCSE), Retrieved January 17, 2011, from http://www.ipn.uni-kiel.de/aktuell/stcse/stcse

6. Snyder, V.W., and Meriam, J.L. (1978). The Mechanics Readiness Test - A Study of Student Preparedness for Mechanics. Proceedings, ASEE Annual Conference and Exposition.

7. Snyder, V.W. (1988). Mechanics Readiness Test: Revisited. Proceedings, ASEE Annual Conference and Exposition.

8. National Science Board, Undergraduate Science, Mathematics and Engineering Education, NSB 86010. 1986, National Science Foundation: Washington, DC.

9. MSBE 1991 forthcoming

10. Ganter, S.L. and Barker, W. (Eds.) (2004). A Collective Vision: Voices of the partner disciplines, MAA Reports, Washington, DC: Mathematical Association of America.

11. National Science Foundation (1996). Shaping the Future: New expectations for undergraduate education in science, mathematics, engineering, and technology. Report of the Advisory Committee for Review of Undergraduate Education, M. George, Chair. Arlington, VA: Author.

12. Armstrong, G., Garner, L., \& Wynn, J. (1994). Our Experience with Two Reformed Calculus Programs. Problems, Resources, and Issues in Mathematics Undergraduate Studies, 4(4), 301-11.

13. Bookman, J. (2000). Program Evaluation and Undergraduate Mathematics Renewal: The impact of calculus reform on student performance in subsequent courses. In S.L. Ganter (Ed.), Calculus Renewal: Issues for undergraduate mathematics education in the next decade (pp. 91-102). New York: Kluwer Academic/Plenum Publishers.

14. Jackson, M.B. (1996). Personal correspondence with author about evaluation of calculus reform at Earlham College, from (Ganter 2001).

15. Keith, S.Z. (1995). How Do Students Feel about Calculus Reform, and How Can We Tell? UME Trends, 6(6), 6 $\& 31$.

16. Ganter, Susan L. (Ed.) (2000). Calculus Renewal: Issues for undergraduate mathematics education in the next decade. New York: Kluwer Academic/Plenum Publishers., 2001

17. Manseur, Z., Ieta, A., and Manseur, R. (2010). Modern Mathematics Requirements in a Developing Engineering Program. Proceedings, ASEE Annual Conference and Exposition.

18. Ganter 2004

19. Hestenes, D., Wells, M., \& Swackhamer, G. (1992). Force concept inventory. The Physics Teacher, 30(3): 141151. 
20. Thornton, R., \& Sokoloff, D. (1990). Learning motion concepts using real-time, microcomputer-based laboratory tools. American Journal of Physics. 58, 858-867.

21. Thornton, 1996 forthcoming

22. Thornton, R., \& Sokoloff, D. (1998). Assessing Student Learning of Newton's Laws: The Force and Motion Conceptual Evaluation and the Evaluation of Active Learning Laboratory and Lecture Curricula. American Journal of Physics, 66, Issue 4, 338-352.

23. S. Ramlo, 2002 forthcoming

24. Steif, P. (2004). Initial Data from a Statics Concept Inventory. Proceedings, ASEE Annual Conference and Exposition.

25. Steif, P.S., and Dantzler, J.A. (2008). A Statics Concept Inventory: Development and Psychometric Analysis. Journal of Engineering Education.

26. Morris and Kraige 1985

27. Hestenes and Wells 1992 -- Hestenes, David, Wells, \& Malcolm (1992). A mechanics baseline test. The Physics Teacher,30:159-166.

28. Danielson, S.G., \& Danielson, E.B. (1992). Problem Solving: Improving a Critical Component of Engineering Education. In: Creativity: Educating world-class engineers. Proceedings, ASEE Annual Conference and Exposition.

29. Roman, A.S., Streveler, R., Steif, P., and Dibello, L. (2010). The Development of a Q-matrix for the Concept Assessment Tool for Statics. Proceedings, ASEE Annual Conference and Exposition.

30. DiBello, L. V., \& Stout, W. Guest Editors' Introduction and Overview: IRT-Based Cognitive Diagnostic Models and Related Methods. Journal of Educational Measurement, 2007: 44(4), p. 285-291.

31. Young and Freedman - University Physics textbook forthcoming

32. Beer and Johnson - Vector Mechanics textbook forthcoming 